\title{
AMMI model to analyse GxE for dual purpose barley in multi-environment trials
}

\author{
R.P.S. Verma, A.S. Kharab, J. Singh, Vishnu Kumar, I. Sharma and Ajay Verma* \\ Indian Institute of Wheat and Barley Research, \\ Karnal 132001 , India. \\ Received: 18-11-2015 \\ Accepted: $15-02-2016$
}

DOI: $10.18805 /$ asd.v35il.9303

\section{ABSTRACT}

The highly significant effects of environments, genotypes and interactions were observed for forage and grain yield. The environmental effects explained the major portion of the total variance as of $82.3 \%$ and $58.8 \%$ respectively. Indicated that the environments were diverse and a major part of variation in yield resulted from environmental changes. The highly significant interaction effects partitioned into IPCA1, IPCA2 and IPCA3, IPCA4; which explained 30.4, 19.4, 14.8 \& $13.2 \%$ for forage and $37.0,17.2,16.1$ and $12.5 \%$ for harvested grain yield. AMMI stability value(ASV) identified promising genotypes G12(UPB 1035), G6(UPB 1034), G7(BH 971) and G13(RD 2857), G7 (BH 971) \& G11(NDB 1570) for forage and grain respectively. AMMI distance (D) marked G3(RD 2035) G9(BH 970) \& G13(RD 2857) for former while genotypes G15(RD 2856) G11(NDB 1570) \& G7(BH 971) for grain yield. GSI score advocated G13(RD 2857), G11(NDB 1570) $\mathrm{G} 3(\mathrm{RD} 2035), \mathrm{G} 5(\mathrm{RD} 2715$ ) and $\mathrm{G} 7(\mathrm{BH} 971$ ), G2(RD 2552) G14(AZAD) desirable genotypes for selection with forage and grain yield. Genotypes with IPCA-1 scores close to zero identified G4(UPB 1036), G7(BH 971), G16(NDB 1566) and G11(NDB 1570), G2 (RD 2552) for forage and yield respectively would have wider adaptation to the tested environments as per AMMI graphical plots.

Key words : AMMI models, AMMI stability value (ASV), Biplot analysis, D(AMMI distance), GxE interaction, Genotypic Selection Index(GSI).

\section{INTRODUCTION}

The Barley (Hordeum vulgare L.) cereal has been cultivated as grain crop for human consumption and as fodder for animal feed in our country (Verma et al., 2011). In the recent years barley can be utilized as green fodder with very limited water supply or less rainfall in these areas (Kumar et al., 2014). Green forage and grain can be utilized for animal fodder/ feed purposes; the barley has shown advantage over oats, because of its dual utilization, faster early growth as well as less water requirement. Dual barley cultivation provides nutrition to the livestock through its green fodder and grains harvested from regenerated crop (Kharab et al., 2013)

The GxE interaction study has recognized as an important aspect for barley improvement programmes as well as the promotions of new cultivars (Bavandpori et al., 2015). Large number of statistical methods are available for analysis of interaction by subdividing the information contained in GxE interaction data matrix into more meaningful components representing real responses of genotypes vis-avis locations (Bose et al., 2014). Methods varied from univariate parametric to multivariate models such as the additive main effect and multiplicative interaction (AMMI) analysis (Mohammadi et al., 2013). More over the static stability is defined by Becker and Leon (1988) as a stable genotype possessing unchanged performance regardless of variation of the environments. Wricke (1962) based on quantifying $\mathrm{G} \times \mathrm{E}$ interaction effects put forward dynamic stability concept. Lin and Binns (1988) proposed the cultivar performance measure $(\mathrm{Pi})$. The better the genotype judged by the smaller the value of Pi. AMMI model is a hybrid model separates the additive variance from the multiplicative variance. The principal component analysis (PCA) applied to the interaction portion to a new set of coordinate axes that explains in more detail the interaction pattern (Mortazavian et al., 2014).

The objectives of the present work have been: (i) compare different measures of the AMMI model, environmental variance and PI statistics, of dual purpose barley genotypes for forage as well as for grain yield (ii) to explore the advantages AMMI graphical biplots to stratify the better-adapted genotypes based on $\mathrm{PC} 1$ and $\mathrm{PC} 2$ scores.

\section{MATERIALS AND METHODS}

The AMMI model for the main and GE interaction effects defined as (Silveira et al., 2013):

$$
Y_{i j}=\mu+\mathrm{gi} .+\mathrm{e} . \mathrm{j}+\sum_{\mathrm{k}=1}^{\mathrm{n}} \lambda_{\mathrm{k}} \gamma_{\mathrm{ik}} \delta_{j k}+\rho_{i j}
$$

*Corresponding author's e-mail: verma.dwr@gmail.com. 
where $\mathrm{Y}_{\mathrm{ij}}$ is the yield of the i-th genotype in the $\mathrm{j}$-th environment; $\mu$ is the grand mean; gi. and e.j are the genotype and environment deviations from the grand mean, respectively; $1_{k}$ is the eigen value of the Principal Component analysis axis $\mathrm{k} ; \mathrm{g}_{\mathrm{k}}$ and $\mathrm{d}_{\mathrm{j} k}$ are the genotype and environment principal component scores (eigenvectors) for axis $\mathrm{k}$; $\mathrm{n}$ is the number of principal components retained in the model and $\mathrm{p}_{\mathrm{ij}}$ is the error term.

The AMMI distance statistic coefficient (D) (Zang et al., 1998) was calculated where D is the distance of the interaction principal component (IPC) point from the origin in space, $\mathrm{n}$ is the number of significant IPCs, and $\gamma_{\text {is }}$ is the score of genotype $\mathrm{i}$ in IPC. The genotype with the lowest value of $\mathrm{D}$ statistic considered as the most stable. Purchase et al., 2000 developed the AMMI stability value (ASV) based on the AMMI model's IPC1 and IPC2 scores for each genotype. The genotypes with the lowest ASV value would be more stable.

AMMI Stability Value $($ ASV $)=$

$\sqrt{\left[\frac{\text { SSIPCA1 }}{\text { SSIPCA2 }} * I P C A 1 \text { score }\right]^{2}+I P C A 2 \text { score }^{2}}$

where SSIPCA1 and SSIPCA2 are sum of squares by the IPCA1, IPCA2 respectively

AMMI Distance $\left(\mathrm{D}_{\mathrm{i}}\right)=$

$$
\sqrt{\sum_{i=1}^{n} \gamma_{i s}^{2}} \quad(\mathrm{i}=1,2,3, \ldots \mathrm{n})
$$

Stability per se might not be the only selection parameter because the most stable genotypes would not necessarily give the best yield performance (Mohammadi $e t$ al., 2007). The need was felt to incorporate both yield and stability in a single index. Cause to it various authors had advocated the different selection criteria for simultaneous selection of yield and stability (Kang, 1993; Farshadfar et al., 2011). Genotypic stability index (GSI) considered the rank of yield of genotypes across environments and rank of AMMI stability value. This index incorporate mean and stability index in a single criteria and calculated as:

$$
\text { GSI }=\text { RASV }+ \text { RY }
$$

where, RASV is the rank of AMMI stability value and RY is the rank of mean yield of genotypes (RY) across environments. Low values show desirable genotypes with high mean yield and stability.

Sixteen barley genotypes were evaluated under national varietal trials carried out under the All India coordinated wheat and barley improvement programme at eleven locations. The experiments were conducted during crop season 2012-13 across locations, viz: Banswara. Bikaner, Durgapura, Faizabad, Hisar, Jalore, Kanpur, Kota, Udaipur, Varanasi and Vijapur. The details of pedigrees for studied genotypes and characteristics of environments are presented in Table 1 for ready reference. The randomized complete block design employed, with four replications. All the cultural practices were carried out as per zone recommendations to harvest good forage and grain yield. Genstat software version 17.1 (VSN) applied to calculate AMMI analysis of data.

\section{RESULTS AND DISCUSSION}

AMMI analysis of variance: The main effects of genotypes, environments and $\mathrm{GxE}$ interaction were highly significant for forage yield at $1 \%$ level of significance (Table $2 a$ ). The highly significant $\mathrm{GxE}$ interaction ranked genotypes differently studied environments. Large portion of total variance was described by the environmental main effect (82.3\%) while the genotypes accounted for $3.0 \%$ of total variation. A large yield variation, explained by environments, indicated that the environments were diverse and a major part of variation in yield resulted from environmental changes

\begin{tabular}{|c|c|c|c|c|c|c|c|}
\hline Code & Genotype & Parentage & Code & Locations & Latitude & Longitude & $\begin{array}{l}\text { Mean Sea } \\
\text { Level }(\mathrm{m})\end{array}$ \\
\hline G1 & RD 2859 & $\mathrm{~K}-551 / \mathrm{PL}-604 / / \mathrm{RD} 2552$ & E1 & Banswara & $23^{\circ} 55^{\prime} \mathrm{N}$ & $74^{\circ} 45^{\prime} \mathrm{E}$ & 216.4 \\
\hline G2 & RD 2552 & RD2035/DL472 & E2 & Bikaner & $28^{\circ} 02^{\prime} \mathrm{N}$ & $73^{\circ} 31^{\prime} \mathrm{E}$ & 225.3 \\
\hline G3 & RD 2035 & RD103/PL101 & E3 & Durgapura & $26^{\circ} 51 \mathrm{~N}$ & $75^{\circ} 47^{\prime} \mathrm{E}$ & 390 \\
\hline G4 & UPB 1036 & JYOTI/(CABUYA/JAZMIN//PETUNIA. 1) & $\mathrm{E} 4$ & Faizabad & $26 \cdot 47 \cdot \mathrm{N}$ & $82^{\circ} 12^{\prime} \mathrm{E}$ & 113 \\
\hline G5 & RD 2715 & RD387/BH602//RD2035 & E5 & Hisar & $29^{\circ} 10^{\prime} \mathrm{N}$ & $75^{\circ} 46^{\prime} \mathrm{E}$ & 215.2 \\
\hline G6 & UPB 1034 & RD2624/DWR46 & E6 & Jalore & $25^{\circ} 34^{\prime} \mathrm{N}$ & $72^{\circ} 62^{\prime} \mathrm{E}$ & 170.5 \\
\hline G7 & BH 971 & HBL $405 / R D / 2683$ & E7 & Kanpur & $26^{\circ} 29^{\prime} \mathrm{N}$ & $80^{\circ} 18^{\prime} \mathrm{E}$ & 125.9 \\
\hline G8 & KB 1238 & $\mathrm{~K} 603 / \mathrm{RD} 2552$ & E8 & Kota & $25^{\circ} 21^{\prime} \mathrm{N}$ & $75^{\circ} 86^{\prime} \mathrm{E}$ & 259.7 \\
\hline G9 & BH 970 & HBL 276/RD/2683 & E9 & Udaipur & $24 \cdot 34^{\prime} \mathrm{N}$ & $70^{\circ} 42^{\prime} \mathrm{E}$ & 582 \\
\hline G10 & RD 2858 & RD2035/UBL-9//VMORALIS & E10 & Varanasi & $25^{\circ} 20^{\prime} \mathrm{N}$ & $83^{\circ} 03^{\prime} \mathrm{E}$ & 75.5 \\
\hline G11 & NDB 1570 & NDB1020/LAKHAN & E11 & Vijapur & $23^{\circ} 35^{\circ} \mathrm{N}$ & $72 \cdot 55^{\circ} \mathrm{E}$ & 41.1 \\
\hline G12 & UPB 1035 & $\begin{array}{l}\text { LAKHAN/ (GIORIA- } \\
\text { BAR/4/SOTOL//2762/BC-B/3/11012.2/...) }\end{array}$ & & & & & \\
\hline G13 & RD 2857 & RD2620/NDB1173//RD2522 & & & & & \\
\hline G14 & $A Z A D$ & $\mathrm{~K} 12 / \mathrm{K} 19$ & & & & & \\
\hline G15 & RD 2856 & RD2620/NDB1173//RD2634 & & & & & \\
\hline G16 & NDB 1566 & BCB128/NDB940 & & & & & \\
\hline
\end{tabular}

TABLE 1: Details of barley genotypes, parentage and environments 
Volume 36 Issue 1 (2016)

TABLE 2 a: AMMI analysis of barley genotypes over locations for forage yield

\begin{tabular}{|c|c|c|c|c|c|}
\hline Source of variation & Degree of freedom & Mean Sum of squares & Variance ratio & $\%$ TSS & $\% \mathrm{GxE}$ \\
\hline Treatments & 175 & 14983 & $67.97 * * *$ & 95.47 & \\
\hline Genotypes & 15 & 5454 & $24.74^{* * *}$ & 2.98 & \\
\hline Environments & 10 & 226077 & $487.68 * * *$ & 82.31 & \\
\hline Block & 33 & 464 & 2.10 & & \\
\hline Interactions & 150 & 1863 & $8.45^{* * *}$ & 10.18 & \\
\hline IPCA 1 & 24 & 3537 & $16.04^{* * *}$ & & 30.37 \\
\hline IPCA 2 & 22 & 2465 & $11.18^{* * *}$ & & 19.40 \\
\hline IPCA 3 & 20 & 2063 & $9.36 * * *$ & & 14.76 \\
\hline IPCA 4 & 18 & 2046 & $9.28 * * *$ & & 13.18 \\
\hline Residuals & 66 & 944 & 4.28 & & \\
\hline Error & 495 & 220 & & & \\
\hline Total & 703 & 3907 & & & \\
\hline
\end{tabular}

$\% \mathrm{TSS}$, percentage of total sum of squares, $\% \mathrm{GxE}$, percentage of $\mathrm{GxE}$ total sum of squares

*** denotes significant at 0.001 level of significance

TABLE 2 b: AMMI analysis of barley genotypes over locations for grain yield

\begin{tabular}{|c|c|c|c|c|c|}
\hline Source of variation & Degree of freedom & Mean Sum of squares & Variance ratio & $\% \mathrm{TSS}$ & $\% \mathrm{GxE}$ \\
\hline Treatments & 175 & 358.6 & $32.55^{* * *}$ & 90.68 & \\
\hline Genotypes & 15 & 501.8 & $45.55^{* * *}$ & 10.88 & \\
\hline Environments & 10 & 4065.3 & $134.44^{* * *}$ & 58.75 & \\
\hline Block & 33 & 30.2 & 2.74 & 1.44 & \\
\hline Interactions & 150 & 97.1 & $8.82^{* * *}$ & 21.06 & \\
\hline IPCA 1 & 24 & 224.7 & $20.40^{* * *}$ & & 37.01 \\
\hline IPCA 2 & 22 & 113.9 & $10.34^{* * *}$ & & 17.20 \\
\hline IPCA 3 & 20 & 117.5 & $10.66^{* * *}$ & & 16.12 \\
\hline IPCA 4 & 18 & 100.8 & $9.15^{* * *}$ & & 12.46 \\
\hline Residuals & 66 & 38.0 & 3.45 & & \\
\hline Error & 495 & 11.0 & & & \\
\hline Total & 703 & 98.4 & & & \\
\hline
\end{tabular}

$\% \mathrm{TSS}$, percentage of total sum of squares, \% GxE, percentage of GxE total sum of squares

*** denotes significant at 0.001 level of significance

(Abdipur and Vaezi, 2014). The multiplicative variance of the treatment sum of squares due to interaction was partitioned into the IPCA1, IPCA2, IPCA3 and IPCA4; which explained $30.4,19.4,14.8$ and $13.2 \%$ of the interaction sum of squares, respectively. More over the first two interaction principal components explained $49.8 \%$ of the interaction sum of squares as reported by Anandan et al., 2009.

The highly significant effects of environments, interactions and genotypes were observed for grain yield. GxE interaction explained $21.1 \%$ of the total variance (Table $2 b)$. Of the total variance, a larger portion was described by the environmental main effect ( $58.8 \%$ ) while the genotypes accounted about $10.9 \%$ of total variation. The significant interaction components i.e. IPCA1, IPCA2 and IPCA3, IPCA4; explained $37.0,17.2,16.1$ and $12.5 \%$ of the interaction sum of squares, respectively. The first two interaction principal components explained $54.2 \%$ of the interaction sum of squares.

Average yield: The forage yield of dual purpose barley genotype ranged from 169.8 to $127.5 \mathrm{q} /$ ha with genotype $\mathrm{RD} 2715$ recorded highest yield closely followed by RD2857 and RD2859 (Table 3a). The lowest yield shown by UPB 1035, UPB 1034 and BH 971.

The grain yield varied from 34 to $23.4 \mathrm{q} /$ ha with genotype RD2035 recorded highest yield closely followed by Azad and RD2552 (Table 3b). The lowest yielder genotypes were RD2857, RD2856 and KB1238.

IPCAs Interaction (crossover and non-crossover interactions): Fifty per cent of genotypes showed positive and negative IPCAlvalues for forage yield. Genotype G14(AZAD) has large negative IPCA1 score also showed positive IPCA4 value. This type of response is referred to as crossover GxE interaction. On the other hand, same sign or near zero scores represent a non-crossover interaction or a proportionate genotype response (Silveira et al., 2013). The genotypes with lower IPCAl scores would produce a lower absolute $\mathrm{G} \times \mathrm{E}$ interaction effect than those with higher absolute IPCAl scores and have less variable yields (more stable) across genotypes (Oliveira et al., 2014). Genotypes $\mathrm{G} 5$ (RD 2715) and $\mathrm{G} 7$ (BH 971) with yields greater than the overall mean and low IPCA1 scores had a combination of high yield and stability performances (Table $3 a$ ). Genotypes $\mathrm{Gl}(\mathrm{RD} 2859$ ) and $\mathrm{Gl3}(\mathrm{RD} 2857$ ) were similar to $\mathrm{G} 9(\mathrm{BH}$ 
970) in the main effect but tended to contribute more to GxE interaction.

Only 10 and 6 genotypes showed positive IPCA1 scores and negative values respectively. Genotype GI(RD 2859) has large negative IPCAl score also showed positive IPCA3 and IPCA4 values. Genotypes G5(RD 2715) and $\mathrm{G7}(\mathrm{BH} 971$ ) with yields greater than the overall mean and low IPCAl scores had a combination of high yield and stability performances (Table $3 \mathrm{~b}$ ).

AMMI stability index (D) incorporates: The scores of significant IPCA towards the interaction SS and the lower D associated high stability across the tested environments and vice versa (Zang et al, 1988). The ranking of genotypes in ascending order of D values are those in $\mathrm{G} 3(3.07)<\mathrm{G} 9(3.35)$ $<$ G13(3.47) < G12(3.73) (Table 3a). Genotypes G12(UPB 1035 ) and G6(UPB 1034) with lowest yield exhibited D values 3.73 and 3.79 respectively. Genotype G14(AZAD) showed smallest negative IPCAl score (-7.03).

The ranking of genotypes for grain yield in ascending D values are G15(1.04) < G11(2.00) < G7 (2.09) $<\mathrm{Gl6}$ (2.13). Genotypes G13(RD 2857) and G8(KB 1238) with lowest yield exhibited D values 2.91 and 3.14 respectively (Table $3 \mathrm{~b}$ ). Genotype G8(KB 1238) showed lower yield and smallest negative IPCAl score $(-2.89)$ as well as larger D (3.14) value. This genotype recognized with stable yield of lower magnitude.

AMMI Stability Value (ASV): ASV is the distance from origin in a two dimensional scatter graph of IPCA l against IPCA2 scores. The IPCA1 score contributes more to GE sum of scores, weighted by the proportional difference between IPCA1 and IPCA2 scores to compensate for the relative contribution of IPCA1 and IPCA 2 towards total GXE sum of squares. Genotype with least ASV score is the most stable, accordingly genotype G12(UPB 1035), followed by G6 (UPB 1034), G7 (BH 971) and G4(UPB 1036) were the most stable, while genotypes G14(AZAD), G15(RD 2856) and G2(RD 2552 ) were undesirable for forage yield (Table 3a). The ranking of genotypes G12 and G6 also supported by criteria based on Static and dynamic stability as per Wricke ccovalence (Mohammadi et al., 2013). However, the genotype G9 ranked as fifth desirable genotype by ASV stood at first and second place by static and dynamic respectively.

Genotypes with lower ASV score, were G13 (RD 2857), followed by G7 (BH 971), G11 (NDB 1570) were the most stable, while genotypes G8(KB 1238), G12(UPB 1035) and G4(UPB 1036) were undesirable (Table $3 b$ ). G15 genotype got first place of choice by static and dynamic concepts irrespective of fifth position by ASV. Genotype $\mathrm{G} 7$ got second rank by ASV and Pi values as well as third by dynamic stability (Mohammadi et al., 2013). G13 identified as most desirable by ASV got supported by third position by static stability.
Genotype Selection Index (GSI): The least GSI is considered as the most stable with high yield. Based on the GSI the most desirable genotype for selection is G13(RD 2857), G11(NDB 1570) followed by G3(RD 2035), G5(RD 2715) (Table 3a). The recommendation of genotype $G 13$ was also supported by cultivar superiority and dynamic stability.

The desirable genotype for high grain yield is G7(BH 971), G2(RD 2552 ) followed by G3(RD 2035), $\mathrm{G} 14(\mathrm{AZAD})$ as reflected by table $3 \mathrm{~b}$. The desirable genotype as per GSI value G7 also got positive weights by cultivars superiority and dynamic stability criteria.

Biplot analysis (Forage harvested): AMMI analysis plots the mean effects of genotypes and locations on the abscissa and IPCA1 scores of both effects, simultaneously on the ordinate (Figure 1). The differences in main effects reflected by displacement along the abscissa, whereas the positions along the ordinate differentiates the interaction effects (Rodriguez et al., 2007). Genotypes G4(UPB 1036), G7(BH 971) and G12(UPB 1035) with IPCA1 scores close to zero have small interactions and have wider adaptation to the tested environments (Mohamadi et al., 2010). The environments showed variability in both main effects and interactions as scattered in all quadrants (Figure 1). The high yielder environments Banaswara observed in quadrant-IV, with maximum interaction effects, negative IPCA1 scores. The high potential environment Jalore and Kota was in quadrant- I, with positive IPCAl and yield. Hisar environment showed lower yield with largest negative IPCA1.

The discriminating ability of the environments can be judged by calculating the distance of each environment from the biplot origin (Oliveira et al., 2014). In this regard, the environments Banswara, Jalore and Hisar are most discriminating as indicated by long distance from the biplot origin. Genotypes with IPCA1 scores $>0$ G13(RD 2857), G5(RD 2715), G8(KB 1238), G10(RD 2858) responded positively (adaptable) to the environments Kota and Jalore that had IPCAl scores $>0$ (positive interaction), but responded negatively to the environments Bikaner and Hisar that had IPCA1 scores $<0$. The reverse applies for the genotypes G4(UPB 1036), Gl(RD 2859), G16(NDB 1566), G9(BH 970) that had IPCA1 scores < 0 (Silveira et al., 2013).

IPCA scores were plotted in the $x$-axis and the $y$ axis respectively (Figure 2). The AMMI analysis for the first Interaction Principal Component (IPC1) captured $30.4 \%$ and the second interaction principal component explained $19.4 \%$ as the first two interaction principal components cumulatively captured $49.8 \%$ of the interaction sum of square. The closer the genotypes to the center the more stable is the genotype and vice versa for unstable genotypes (Purchase et al., 2000). The G6(UPB 1034) and G12(UPB 1035) located near to the origin implies its 


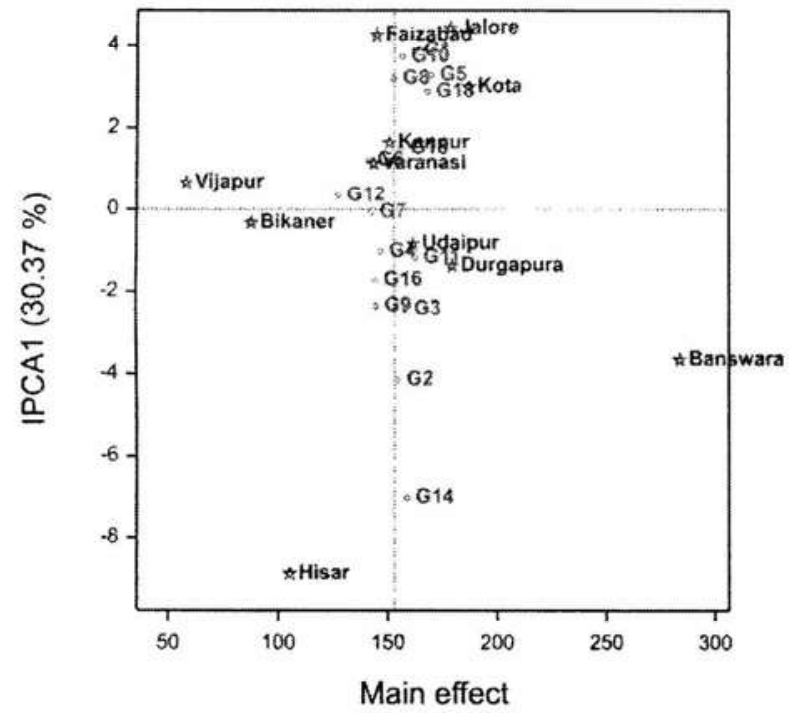

FIG 1: First principal axis of interaction (PCA1) versus forage yield of genotypes

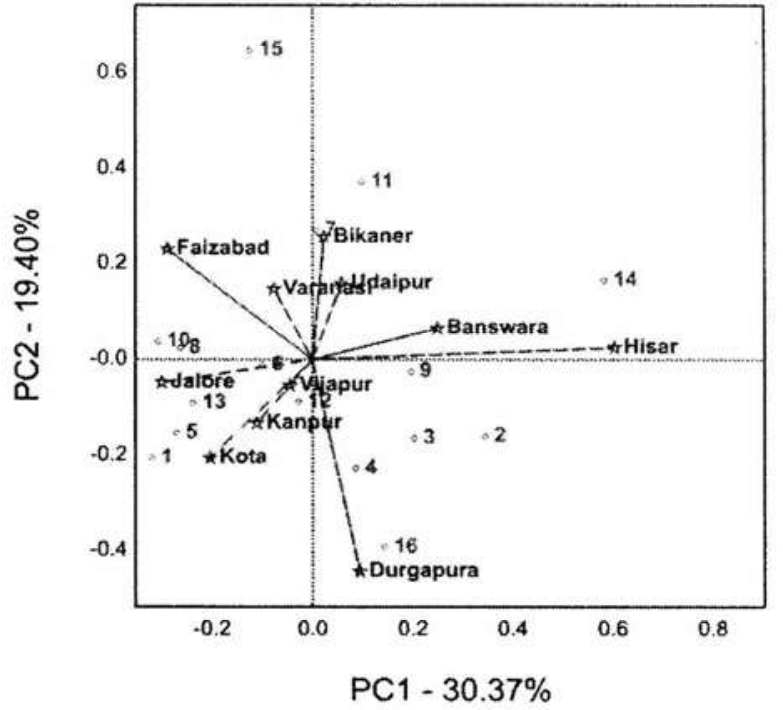

FIG 2: PCA1 versus PCA2 for forage yield of genotypes

Legends for figure (Genotypes depicted by red colour circles and environments by blue colour stars)

\begin{tabular}{llllllll}
\hline G1 & G2 & G3 & G4 & G5 & G6 & G7 & G8 \\
RD 2859 & RD 2552 & RD 2035 & UPB 1036 & RD 2715 & UPB 1034 & BH 971 & KB 1238 \\
G9 & G10 & G11 & G12 & G13 & G14 & G15 & G16 \\
BH 970 & RD 2858 & NDB 1570 & UPB 1035 & RD 2857 & AZAD & RD 2856 & NDB 1566 \\
\hline
\end{tabular}

stable behavior as compared to the barley genotypes G15(RD 2856), G11(NDB 1570), G14(AZAD), G16(NDB 1566), G1(RD 2859) located distant from the origin. The cosine of angle involving a pair of environment or genotype vectors approximates correlation between them (Mladenov et al., 2012). An acute angle (less than $90^{\circ}$ ) indicates a strong positive correlation between environments (Banswara, Hiar), (Bikaner, Udaipur), (Faizabad, Varanasi); an angle close to $90^{\circ}$ indicates the environments are not correlated (Kota, Faizabad), (Jalore, Durgapura) ; whereas, an obtuse angle close to $180^{\circ}$ represents a strong negative relationship (Varanasi, Durgapura) and (Jalore, Hisar). Vectors corresponding to (Faizabad, Hisar) showed angles more than $90^{\circ}$ angle suggesting that these environments tend to discriminate among genotypes in a similar manner.

Biplot analysis (Grain yield): Genotypes G11(NDB 1570) and G2(RD 2552 ) with IPCA1 scores close to zero have small interactions and have wider adaptation to the tested environments (Figure 3). The environments were scattered in all quadrants. The high yielder environments Udaipur and Hisar were seen in quadrant-IV, with maximum interaction effects, high negative IPCA-1 scores. The low potential environment Banswara was in quadrant-III, with low negative IPCA1 and yield. Kota environment showed higher yield potential with highest positive IPCA1.
The environments Bikaner, Hisar and Vijapur are most discriminating as indicated by long distance from the biplot origin. Genotypes G7(BH 971), G3(RD 2035), G9(BH 970), G6(UPB 1034), G4(UPB 1036) with IPCA1 scores $>0$ responded positively (adaptable) to the Kota \& Jalore environments that had IPCA1 scores $>0$ (positive interaction), but responded negatively to the environments Banswara, Bikaner, Faizabad with IPCAI scores $<0$. More over the reverse behavior seen for the genotypes G15(RD 2856), G5(RD 2715), G10(RD 2858),Gl(RD 2859) that had IPCA1 scores $<0$.

First Interaction Principal Component (IPCl) captured $37 \%$ and the second interaction principal component explained $17.2 \%$ as the first two interaction principal components cumulatively captured $54.2 \%$ of the interaction sum of square (Figure 4). The G13(RD 2857), G15(RD 2856 ) and G16(NDB 1566) located near to the origin implies its stable behavior as compared to the barley genotypes G12(UPB 1035), G5(RD 2715), G8(KB 1238), G14(AZAD), G3(RD 2035) located distant from the origin. An acute angle (less than $90^{\circ}$ ) indicates a strong positive correlation between environments (Banswara, Durgapura), (Bikaner, Udaipur), (Kota, Jalore); an angle close to $90^{\circ}$ indicates the environments are not correlated (Kanpur, Hisar); whereas, an obtuse angle close to $180^{\circ}$ represents a strong negative relationship (Kanpur, Bikaner). Vectors 


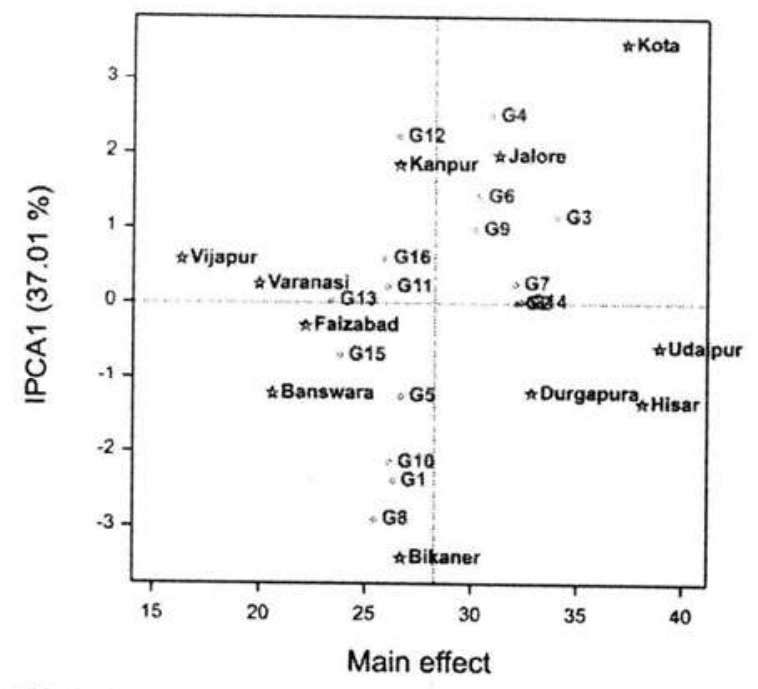

FIG 3: PCA1 versus mean yield

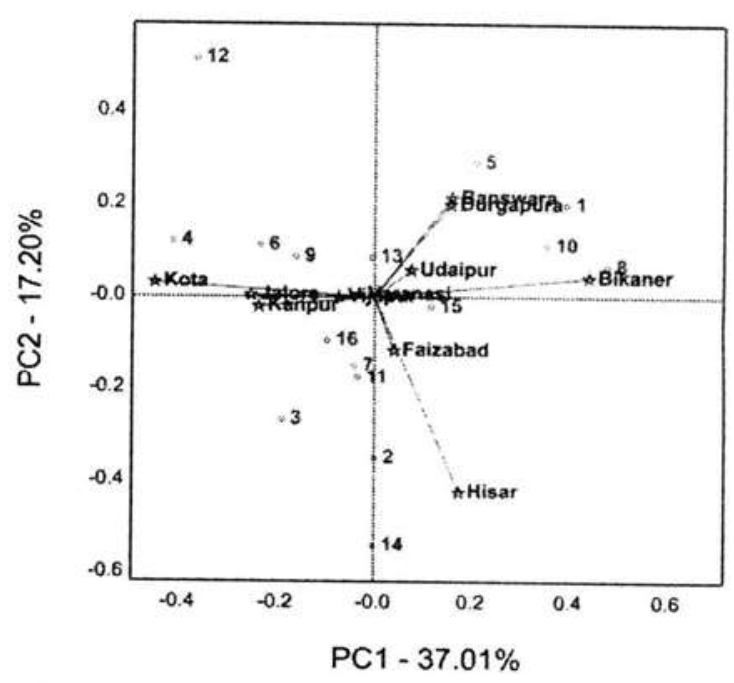

FIG 4: PCA1 versus PCA2 scores for yield

Legends for figure (Genotypes depicted by red colour circles and environments by blue colour stars)

\begin{tabular}{llllllll}
\hline G1 & G2 & G3 & G4 & G5 & G6 & G7 & G8 \\
RD 2859 & RD 2552 & RD 2035 & UPB 1036 & RD 2715 & UPB 1034 & BH 971 & KB 1238 \\
G9 & G10 & G11 & G12 & G13 & G14 & G15 & G16 \\
BH 970 & RD 2858 & NDB 1570 & UPB 1035 & RD 2857 & AZAD & RD 2856 & NDB 1566 \\
\hline
\end{tabular}

corresponding to (Kota, Hisar) showed angles more than $90^{\circ}$ angle suggesting that these environments tend to discriminate among genotypes in a similar manner.

\section{ACKNOWLEDGEMENT}

The support provided by Dr A. Sarkar, ICARDA New Delhi and Dr Murari Singh, Senior Biometrician,
ICARDA Jordan is sincerely acknowledged by authors. The multi-environment testing of barley genotypes was performed within the AICW\&BIP project at centers across the country. Authors are grateful to all the staff of centers under AICW\&BIP for the hard work to carry the field evaluation and data recording.

\section{REFERENCES}

Abdipur, M. and Vaezi, B. (2014). Analysis of the genotype-by-environment interaction of winter barley tested in the Rain-fed Regions of Iran by AMMI Adjustment. Bulgarian Journal of Agricultural Science. 20: 421-427.

Anandan, A., Eswaran, R., Sabesan, T. and Prakash, M. (2009). Additive main effects and multiplicative interactions analysis of yield performances in rice genotypes under coastal saline environments. Advances in Biological Research. 3: $43-47$

Bavandpori, F., Ahmadi, J. and Hossaini, S. (2015). Yield stability analysis of bread wheat lines using AMMI Model. Agricultural Communications. 3: 8-15.

Becker, H.C. and Léon, J. (1988). Stability analysis in plant breeding. Plant Breeding. 101:1-23.

Bose, L. K., Jambhulkar, N., Pande, N. K. and Singh, O. N. (2014). Use of AMMI and other stability statistics in the simultaneous selection of rice genotypes for yield and stability under direct-seeded conditions. Chilean Journal of Agricultural Research. 74:3-9.

Farshadfar, E., Mahmodi, N. and Yaghotipoor, A. (2011). AMMI stability value and simultaneous estimation of yield and yield stability in bread wheat (Triticum aestivum L.). Australian Journal of Crop Science. 5: 1837-1844.

Kharub, A.S., Verma,R. P. S., Kumar, D., Kumar,V.,Selvakumar, R. and Sharma, I. (2013). Dual purpose barley (Hordeum vulgare L.) in India: Performance and potential. $J$ Wheat Res. 5: 55-58.

Kumar, V., Khippal, A., Singh, J., Selvakumar, R., Malik, R., Kumar, D., Kharub, A. S, Verma, R. P. S. and Sharma, 1. (2014). Barley research in India: Retrospect \& prospects. $J$ Wheat Res. 6:1-20.

Lin, C. S. and Binns, M. R. (1988). A superiority measure of cultivar performance for cultivar x location data. Can J Plant Sci. 68: 193-198. 
Mladenov, V., Banjac, B. and Miloševic, M. (2012). Evaluation of yield and seed requirements stability of bread wheat (Triticum aestivum L.) via AMMI model. Turkish Journal of Field Crops. 17: 203-207.

Mohammadi, M., Karimizadeh, R., Noorinia, A.A., Ghojogh, H., Hosseinpour, T., Khalilzadeh, G.R., Mehraban, A., Roustaii, M. and Hasanpor, H. M. (2013) Analysis of yield stability in multi-environment trials of barley (Hordeum vulgar L.) genotypes using AMMI model Curr. Opin. Agric. 2: 20-24.

Mohammadi, R., Mozaffar, R. M., Yousef, A., Mostafa, A. and Amri, A. (2010). Relationships of phenotypic stability measures for genotypes of three cereal crops. Can J Plant Sci. 90: 819-830.

Mohammadi, R., Abdulahi,A., Haghparast, R. and Armion, M. (2007). Interpreting genotype-environment interactions for durum wheat grain yields using non-parametric methods. Euphytica. 157:239- 251.

Mortazavian, S. M. M., Nikkhah, H. R., Hassani, F. A., Sharif-al-Hosseini, M., Taheri, M. and Mahlooji, M. (2014). GGE biplot and AMMI analysis of yield performance of barley genotypes across different environments in Iran. Jour Agr Sci Tech. 16: 609-622.

Oliveira, E. J. de, de Freitas, J. P. X. and de. Jesus, O. N. (2014). AMMI analysis of the adaptability and yield stability of yellow passion fruit varieties. Scientia Agricola. 71:139-145.

Purchase, J.L., Hatting, H. and Vandeventer, C.S. (2000). Genotype $\times$ environment interaction of winter wheat (Triticum aestivum L.) in South Africa: Stability analysis of yield performance. South African Journal of Plant and Soil. 17: 101-107.

Rodriguez, M., Rau, D., Papa, R. and Attene, G (2007). Genotype by environment interactions in barley (Hordeum vulgare L.): different responses of landraces, recombinant inbred lines and varieties to Mediterranean environment. Euphytica. 163: 231-247.

Silveira, L.C.I., Kist, V., Paula, T.O.M., Barbosa, M.H.P, Peternelli, L.A. and Daros, E. (2013). AMMI analysis to evaluate the adaptability and phenotypic stability of sugarcane genotypes. Scientia Agricola. 70: 27-32.

Verma R.P.S., Kharub, A.S., Kumar, D., Sarkar, B., Selvakumar, R., Singh, R., Malik, R., Kumar, R. and Sharma, I. (2011). Fifty years of coordinated barley research in India. Directorate of Wheat Research, Karnal-132001. Research Bulletin No. 27: 46.

VSN International. (2014). GenStat for Windows 17th Edition. VSN International, Hemel Hempstead, UK.

Wricke, G (1962). Z. Flanzenzuchlung, Uber line Method Zur Erfassung der okologischen Strechbreta in Feldersuchen.

Zhang, Z., Lu, C. and Xian, Z.H. (1998). Analysis of variety stability based on AMMI model. Acta Agron Sin. 24: 304-309. 